\title{
Article \\ Efficacy of Docosahexaenoic Acid for the Prevention of Necrotizing Enterocolitis in Preterm Infants: A Randomized Clinical Trial
}

\author{
Mariela Bernabe-García ${ }^{1}$, Philip C. Calder ${ }^{2,3,4, *}$, Raúl Villegas-Silva ${ }^{5}$, Maricela Rodríguez-Cruz ${ }^{1}$, \\ Luis Chávez-Sánchez ${ }^{6}$, Leonardo Cruz-Reynoso ${ }^{7}$, Leovigildo Mateos-Sánchez ${ }^{8}$, Gabriel Lara-Flores ${ }^{8}$, \\ Augusto R. Aguilera-Joaquín ${ }^{7}$ and Luisa Sánchez-García ${ }^{7}$
}

check for

updates

Citation: Bernabe-García, M.; Calder, P.C.; Villegas-Silva, R.;

Rodríguez-Cruz, M.; Chávez-Sánchez,

L.; Cruz-Reynoso, L.;

Mateos-Sánchez, L.; Lara-Flores, G.;

Aguilera-Joaquín, A.R.;

Sánchez-García, L. Efficacy of

Docosahexaenoic Acid for the

Prevention of Necrotizing

Enterocolitis in Preterm Infants: A

Randomized Clinical Trial. Nutrients

2021, 13, 648. https://doi.org/

$10.3390 /$ nu13020648

Academic Editor: Yves

Marc Dupertuis

Received: 23 January 2021

Accepted: 12 February 2021

Published: 17 February 2021

Publisher's Note: MDPI stays neutral with regard to jurisdictional claims in published maps and institutional affiliations.

Copyright: (c) 2021 by the authors. Licensee MDPI, Basel, Switzerland. This article is an open access article distributed under the terms and conditions of the Creative Commons Attribution (CC BY) license (https:// creativecommons.org/licenses/by/ $4.0 /)$.
1 Unidad de Investigación Médica en Nutrición, UMAE Hospital de Pediatría, CMN Siglo XXI, Instituto Mexicano del Seguro Social, México City 06720, Mexico; marielabernabe1@gmail.com (M.B.-G.); maricela.rodriguez.cruz@gmail.com (M.R.-C.)

2 School of Human Development and Health, Faculty of Medicine, University of Southampton, Southampton SO16 6YD, UK

3 Institute for Life Sciences, University of Southampton, Southampton SO17 1BJ, UK

4 NIHR Southampton Biomedical Research Centre, University Hospital Southampton NHS Foundation Trust and University of Southampton, Southampton SO16 6YD, UK

5 Neonatología, Hospital Infantil de México Federico Gómez, México City 06720, Mexico; raul.villegassilva@gmail.com

6 Unidad de Investigación Médica en Inmunología, UMAE Hospital de Pediatría, CMN Siglo XXI, Instituto Mexicano del Seguro Social, México City 06720, Mexico; luischz@yahoo.com

7 Unidad de Cuidados Intensivos Neonatales, UMAE Hospital de Gineco-Obstetricia No.3, CMN La Raza, Instituto Mexicano del Seguro Social, México City 02990, Mexico; drleonardocruz@yahoo.com.mx (L.C.-R.); draguilera357@gmail.com (A.R.A.-J.); lsanchezg60@hotmail.com (L.S.-G.)

8 Unidad de Cuidados Intensivos Neonatales, UMAE Hospital de Gineco-Obstetricia N ${ }^{\circ} 4$ "Luis Castelazo Ayala", Instituto Mexicano del Seguro Social, México City 01090, Mexico; lmateos95@yahoo.com.mx (L.M.-S.); drdebebes@gmail.com (G.L.-F.)

* Correspondence: pcc@soton.ac.uk

Abstract: Necrotizing enterocolitis (NEC) is an inflammatory bowel disease and a leading cause of morbidity and mortality in preterm infants. In this study, a randomized double-blind parallel-group (1:1) trial was carried out in two neonatal intensive care units of two tertiary hospitals. Two hundred and twenty-five preterm newborns with an expected functional gastrointestinal tract were recruited and received an enteral dose of $75 \mathrm{mg}$ of docosahexaenoic acid (DHA) $/ \mathrm{kg}$ body weight or high-oleic sunflower oil daily for 14 days from the first enteral feed after birth. Confirmed NEC was evaluated with Bell's scale from stage $\geq$ IIa. Two hundred and fourteen randomized infants were analyzed in terms of the intent-to-treat (DHA-group: $n=105$; control-group: $n=109$ ); data for two hundred infants were analysed per protocol. Confirmed NEC was lower in infants from the DHA-group compared with the control-group ( $0 / 100$ vs. $7 / 100 ; p=0.007)$, with $\mathrm{RR}=0.93$ (95\% CI 0.881 to 0.981 ), risk difference $=-7 \%$, $(95 \% \mathrm{CI}-12.00$ to -1.99$)$, and number needed-to-treat $=15$ (95\% CI 8.3 to 50). Intent-to-treat analysis showed a lower level of treatment failure in the DHA-group compared with the control-group (6/105 (6\%) vs. 16/109 (15\%); $p=0.03, \mathrm{RR}=0.905,(95 \% \mathrm{CI} 0.826$ to 0.991$)$ ). The results after multivariate-regression analysis remained significant. Adverse events (apart from the incidence of NEC) were not different between groups. A daily dose of DHA for 14 days starting with the first enteral feed may prevent NEC in preterm infants.

Keywords: very low birth weight; infant; prematurity; necrotizing enterocolitis; inflammation; DHA; omega-3; n-3 fatty acids; neonatal intensive care unit; hospital stay

\section{Introduction}

Necrotizing enterocolitis (NEC) is a multifactorial inflammatory bowel disease. This condition starts with an unbalanced pro-inflammatory response that rapidly evolves with- 
out warning into a necrotic bowel and/or death. Most cases occur in preterm infants (birth weight $<1500 \mathrm{~g}$ or $<32$ weeks of gestational age) [1,2], and NEC remains a leading cause of morbidity and mortality in neonatal intensive care units (NICUs) worldwide [3]. Moreover, survivors of NEC have long-term complications and high medical costs [4].

The pathophysiology of NEC involves bowel and immune immaturity, including scarce mucus, low secretory immunoglobulin A, poor closure between enterocytes along with an altered intestinal bacterial diversity (dysbiosis) related to antibiotic administration, and the type of feeding, among other factors, especially in formula-fed infants [5,6]. Once developed, NEC is managed through support measures [1]. Therefore, strategies to prevent NEC are needed.

Docosahexaenoic acid (DHA), which is an n-3 long-chain polyunsaturated fatty acid (LC-PUFA), is accreted during the last trimester of gestation [7]. This accretion is cut-off by a preterm birth, so preterm infants can become deficient in DHA after birth, even if they receive LC-PUFA supplemented formula [8]. DHA is found in human breast milk, which reduces the risk of NEC [7]. A global survey of human breast milk fatty acids using data from 65 studies involving 2474 women reported a mean (SD) DHA content of $0.32(0.22)$ percent of total fatty acids, with a range of 0.06 to $1.4 \%$ of total fatty acids [9]. The DHA content of breast milk changes with the duration of lactation and is highest in colostrum [10]. Some, but not all, infant formulas contain DHA, typically including about $0.3 \%$ of total fatty acids [11]. DHA exhibits actions that can modulate exacerbated inflammatory responses in several neonatal morbidities, including NEC [12].

Therefore, the aim of this study was to evaluate the efficacy of the enteral administration of DHA to prevent NEC in preterm infants; considering that preterm formula may be an inflammatory stimulus, the intervention started with the first enteral feed after birth.

\section{Materials and Methods}

\subsection{Study Design and Participants}

A randomized double-blind parallel-group clinical trial was conducted in preterm newborn infants with birthweight $\leq 1500 \mathrm{~g}$, but $\geq 1000 \mathrm{~g}$, with an expected functional gastrointestinal tract; infants were recruited between October 2012 and October 2017 from two hospitals affiliated with the Instituto Mexicano del Seguro Social (IMSS) in México City. Infants with congenital malformations, a need for major surgery, or periventricular/intraventricular hemorrhage grade $\geq$ II were excluded. At recruitment, none of the mothers were taking n-3 fatty acid supplements or had taken them during pregnancy.

This research was carried out in accordance with The Code of Ethics of the World Medical Association [13] and was approved by the Ethics Committee, National Committee of Scientific Research from IMSS (institutional code CNIC-2012-785-007). The trial was registered at clinicaltrials.gov (NCT01745510) prior to the enrolment of the first participant. Written informed consent was obtained from both parents/guardians (overseen by two witnesses) prior to infant randomization, conforming to the Regulation of the General Law of Health, in matters of Research for Health in Mexico [14].

\subsection{Randomization and Intervention}

Randomization was performed using the Random Allocation Software version 1 for parallel groups, with a 1:1 intervention ratio and block sizes of 10 patients per birthweight (1000-1250 g and from 1251-1500 g) [15]; each hospital had its own independent randomization assignment. The intervention groups received a code (A or B) and were packed into opaque envelopes by a researcher who did not participate in the fieldwork; all other clinical and research staff were blind to allocation.

Preterm infants received a daily dose of $75 \mathrm{mg}$ of DHA $/ \mathrm{kg}$ of body weight (DHAgroup) from a DHA-rich algal oil diluted in high-oleic sunflower oil as a vehicle (Neuromins ${ }^{\circledR}$ for Kids life's DHA ${ }^{\circledR}$; DSM Nutritional Products Inc., Parsippany, NJ, USA) or sham oil (control group; high-oleic sunflower oil; PROGELA SA, México City, Mexico) for 14 days, similar in colour and consistency. The fatty acid composition of the oils is shown in Table 1. 
Table 1. Fatty acid composition of the intervention (docosahexaenoic acid (DHA)-rich) and sham oils (\%wt of total fatty acids).

\begin{tabular}{ccc}
\hline \multirow{2}{*}{ Fatty Acid } & \multicolumn{2}{c}{ GROUP } \\
\cline { 2 - 3 } & DHA Intervention (Algal Oil) & Control (High-Oleic Sunflower Oil) \\
\hline Capric & 1.0 & 0.0 \\
Lauric & 4.3 & 0.0 \\
Myristic & 14.0 & 0.1 \\
Palmitic & 12.2 & 5.2 \\
Palmitoleic & 1.9 & 0.1 \\
Stearic & 0.7 & 3.8 \\
Oleic & 18.9 & 58.9 \\
Linoleic & 1.3 & 29.2 \\
Gamma-Linolenic & 0.4 & 0.3 \\
Alpha-Linolenic & $<0.1$ & 1.2 \\
Eicosenoic & $<0.1$ & 0.3 \\
Arachidonic & $<0.1$ & 0.0 \\
Eicosapentaenoic & $<0.1$ & 0.0 \\
Behenic & 0.2 & 0.7 \\
Docosahexaenoic & 44.3 & 0.0 \\
Nervonic & 0.1 & 0.0 \\
\hline These fatty acids represent more than $99 \%$ of the total fatty acid profile.
\end{tabular}

These fatty acids represent more than $99 \%$ of the total fatty acid profile.

Every 3 days, research staff updated the infant's weight to modify the dosage. Research staff directly observed administration of the oils, which were given from the first feed after birth, being flushed through an orogastric tube before the milk and/or enteral formula. The DHA dose mimics the high physiological supply of DHA from human milk [9] and has been well-tolerated in previous studies in neonates [16,17]. DHA administration was suspended if any persisting bleeding was identified, if the platelet count was $<80,000 \mathrm{~mm}^{3}$, or if the infant was fasting due to acute illness.

\subsection{Main Outcome Measure: Confirmed Necrotizing Enterocolitis}

Confirmed NEC was determined prospectively using Bell's scale modified by Walsh [18]. Briefly, stages Ia to Ib are suspected NEC, stages IIa to IIb are confirmed NEC, and severe/advanced NEC is from stage IIIa with an intact bowel and stage IIIlb with a perforated bowel. The attendant neonatologist identified the concordance of the $\mathrm{X}$ rays with systemic and intestinal signs. Then, a second neonatologist confirmed or discarded the diagnosis. In the case of non-concordance, a third neonatologist decided the diagnosis. Confirmed NEC was considered from stage IIa or greater [18].

\subsection{Adverse Events}

Adverse events included a platelet count $<80,000 \mathrm{~mm}^{3}$ (collected from routine biochemical analyses), bleeding events such as periventricular/intraventricular hemorrhage grade $\geq$ II, pulmonary and gastric bleeding, and death.

\subsection{Clinical Course and Management}

At recruitment, infant sex, gestational age, presence of severe asphyxia at birth, being small for the gestational age, being a twin or singleton, and the severity of disease measured with the Clinical Risk Index for Babies (CRIB) Score [19] were recorded. The clinical course, such as the presence of patent ductus arteriosus, respiratory distress syndrome, suspected sepsis, and apnea events, as well as medical management, such as antibiotics, ibuprofen, omeprazole, red blood cell (RBC) transfusions, and the duration of low oxygen saturation $\left(\mathrm{SpO}_{2}<85 \%\right)$, were recorded.

Details on nutritional support were collected until hospital discharge. Patients who required total/partial parenteral nutrition (TPN) received a $20 \%$ soybean oil-based lipid emulsion. Intake of the mother's own milk was recorded. Data are presented for the first 2 weeks of the intervention and total hospital stay. Hospital discharge happened when the 
infant was able to maintain a stable body temperature and had reached a body weight of at least $1.8 \mathrm{~kg}$.

\subsection{Fatty Acid Profile in Erythrocytes and Human Milk}

The fatty acid profile of infant erythrocytes was measured. To avoid additional punctures for research purposes, an additional blood sample was collected in ethylenediaminetetraacetic acid tubes when consultants ordered blood for clinical tests. The method employed to measure the erythrocyte fatty acid profile by gas chromatography has been reported elsewhere [17]. Briefly, after total lipid extraction from erythrocytes by the modified Folch method, fatty acid methyl esters (FAMEs) were produced and separated by gas chromatography (Agilent 7820A, Agilent Technologies, Santa Clara, CA, USA). The identification of FAMEs was conducted according to the retention time from specific FAME standards (Poly Sciences, Niles, IL, USA) and heptadecanoic acid was employed as an internal standard [20]. The fatty acid profile of human milk samples was determined using the same methods. Fatty acids are reported as the weight percentage of total fatty acids (\%wt of total fatty acids). The fatty acid profile of the enteral formula was estimated from the composition reported by the manufacturers.

\subsection{Sample Size and Statistical Analysis}

The sample size was estimated with a two-sided $\alpha=0.05$ and a power $=80 \%$, where P1 for control $=15 \%$ and P2 for DHA intervention $=4 \%$. A sample size of 111 patients $/$ group was obtained. However, a bivariate interim analysis performed after 5 years identified significant differences between groups and recruitment was stopped.

IBM SPSS software version 21 (IBM Corp., Armonk, NY, USA) was used for data analysis. The data distribution was inspected. Data are presented as the median and interquartile range (quartile 25 , quartile 75 ) or (minimum, maximum) for variables with scarce patients. DHA and control groups were compared with the Mann-Whitney-U test, Chi-square test, and relative risk (RR) with a 95\% confidence interval (CI). However, as both groups had similar covariates, the infants in the control-group who developed NEC were also compared as an independent group with the DHA-group and the remainder of the infants in the control-group without NEC, using Fisher's Exact, Kruskal-Wallis, and Mann-Whitney-U tests. Multivariate analysis with decision trees using Chi-square automatic interaction detection (CHAID) regression was applied to identify the predictors of confirmed NEC. In all cases, a $p$ value $<0.05$ was considered to be statistically significant. Those preterm infants who received at least one dose of DHA or sham were included in the intent-to-treat analysis using the Chi- square test and RR (95\% CI).

\section{Results}

From the two hospitals, 225 preterm infants were recruited and randomized; 214 infants received at least one dose of DHA or sham and from them, 100 infants per group were analysed per protocol (Figure 1). Of these 200 infants, 179 were recruited at one hospital ( $n=90$ in the control-group, $n=89$ in the DHA-group) and 21 at the other $(n=10$ in the control-group, $n=11$ in DHA-group). Baseline characteristics of the infants were comparable between DHA and control groups (Table 2). 


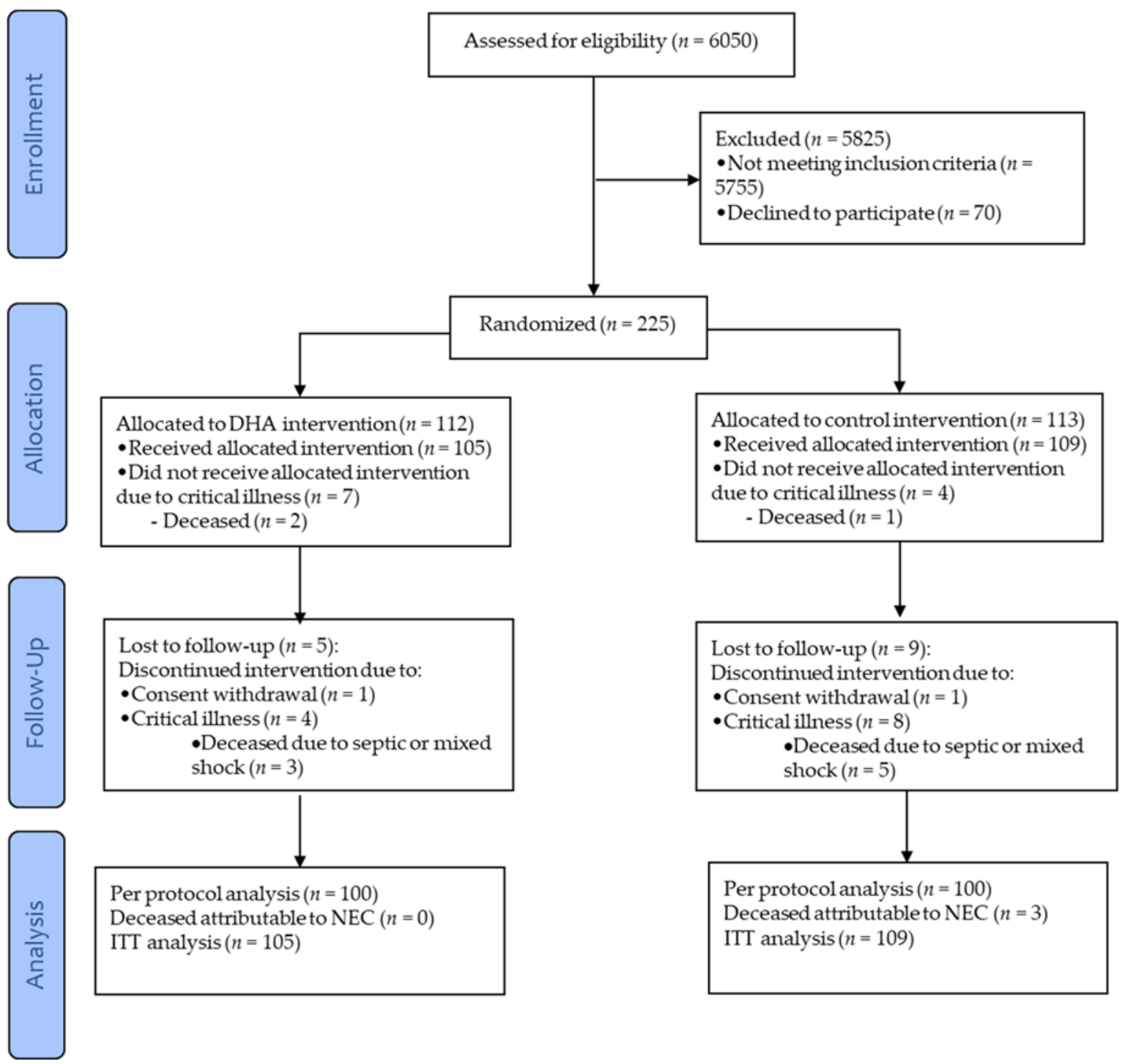

Figure 1. CONSORT diagram depicting the flow of the infants through the study. DHA, docosahexaenoic acid; NEC, necrotizing enterocolitis; and ITT, intent-to-treat.

Table 2. Characteristics of the preterm infants.

\begin{tabular}{cccc}
\hline & \multicolumn{2}{c}{ GROUP } & \\
\cline { 2 - 3 } & DHA & Control \\
& $\boldsymbol{n}=\mathbf{1 0 0}$ & & \\
& At Birth & & \\
\hline Born by cesarean section, $n(\%)$ & $96(96)$ & $99(99)$ & 0.391 \\
Received antenatal steroid, $n(\%)$ & $48(48)$ & $42(42)$ & 0.601 \\
Gestational age, weeks & $30(29,32)$ & $31(30,32)$ & 0.513 \\
Male sex, $n(\%)$ & $52(52)$ & $47(47)$ & 0.572 \\
Apgar score at minute 5 $\geq 7, n(\%)$ & $96(96)$ & $95(95)$ & 1.000 \\
\hline & At Baseline & & \\
\hline Corrected gestational age, weeks & $31.0(29.8,32.3)$ & $31.1(28.0,32.5)$ & 0.306 \\
\hline
\end{tabular}

Data are presented as the median $(\mathrm{Q} 25, \mathrm{Q} 75)$ unless otherwise stated. 


\subsection{Confirmed Necrotizing Enterocolitis}

Seven infants developed NEC and all were in the control-group. Therefore, infants with NEC were separated from the rest of the infants in the control-group, but the characteristics remained similar (Table 3). All infants who developed NEC had sepsis prior to developing NEC and all were from one of the two hospitals; this was the hospital that recruited the higher number of infants.

Table 3. Clinical course and medical management during the hospital stay of the very low birth weight infants stratified by confirmed necrotizing enterocolitis (NEC).

\begin{tabular}{|c|c|c|c|c|}
\hline & \multicolumn{3}{|c|}{ GROUP } & \multirow[b]{2}{*}{$p$} \\
\hline & $\begin{array}{c}\text { DHA } \\
n=100\end{array}$ & $\begin{array}{c}\text { Control } \\
n=93\end{array}$ & $\begin{array}{l}\text { NEC } \\
n=7\end{array}$ & \\
\hline Birthweight 1000-1250 g, $n(\%)$ & $40(40)$ & $44(47)$ & $4(57)$ & \\
\hline Birthweight $1251-1500 \mathrm{~g}, n(\%)$ & $60(60)$ & $49(53)$ & $3(43)$ & 0.460 \\
\hline Small for gestational age, $n(\%)$ & $14(14)$ & $12(13)$ & $1(14)$ & 0.974 \\
\hline Twins, $n(\%)$ & $23(23)$ & $30(32)$ & $2(29)$ & 0.354 \\
\hline Severe asphyxia at birth, $n(\%)$ & $9(9)$ & $10(11)$ & 0 & 0.627 \\
\hline Severity of disease (CRIB) at baseline & $2.0(1,5.0)$ & $1.0(1,4.5)$ & $1.0(0,6.0)$ & 0.760 \\
\hline Hemoglobin at baseline, $\mathrm{g} / \mathrm{dl}$ & $\begin{array}{c}15.7 \\
(14.2,17.7)\end{array}$ & $\begin{array}{c}16.5 \\
(14.8,18.0)\end{array}$ & $\begin{array}{c}14.1 \\
(12.9,16.8)\end{array}$ & 0.150 \\
\hline Respiratory distress syndrome, $n(\%)$ & $90(90)$ & $84(90)$ & $7(100)$ & 0.681 \\
\hline Suspected or confirmed sepsis, $n(\%)$ & $66(66)$ & $57(61)$ & $7(100)$ & 0.112 \\
\hline PDA, $n(\%)$ & $18(18)$ & $21(23)$ & $3(43)$ & 0.259 \\
\hline Apnea, $n(\%)$ & $36(36)$ & $24(26)$ & $4(57)$ & 0.110 \\
\hline Apnea events in week $1, n$ & $1(1,2)$ & $1(1,2)$ & 1 & 0.780 \\
\hline Apnea events in week $2, n$ & $2(1,2)$ & $1.5(1,3)$ & $1(1,1.5)$ & 0.669 \\
\hline Apnea events during hospitalization, $n$ & $3.0(2,5)$ & $3.0(1,7)$ & $4.5(1.3,8)$ & 0.881 \\
\hline $\begin{array}{l}\text { Requirement for phase III } \\
\text { ventilator support, } n(\%)\end{array}$ & $65(66)$ & $62(67)$ & $6(86)$ & 0.552 \\
\hline Duration with $\mathrm{SpO}_{2}<85 \%$ in week $1, \mathrm{~h}$ & $5.5(2.0,12.0)$ & $4(2.0,6.0)$ & 0 & 0.219 \\
\hline Duration with $\mathrm{SpO}_{2}<85 \%$ in week $2, \mathrm{~h}$ & $7.0(5.0,13.5)$ & $4(3.5,8.0)$ & 0 & 0.146 \\
\hline Retinopathy of the prematurity, $n(\%)$ & $23(23)$ & $23(25)$ & $0^{*}$ & 0.325 \\
\hline Antibiotics used, $n(\%)$ & $97(97)$ & $92(99)$ & $7(100)$ & 0.589 \\
\hline Postnatal age at antibiotic start, $\mathrm{h}$ & $8(4,24)$ & $8(4,24)$ & $8(4,48)$ & 0.937 \\
\hline Antibiotic duration, days & $26(17,42)$ & $27(19,42)$ & $28(25,38)$ & 0.950 \\
\hline Postnatal steroid use, $n(\%)$ & $21(21)$ & $21(23)$ & $3(43)$ & 0.408 \\
\hline Ibuprofen use, $n(\%)$ & $9(9)$ & $6(7)$ & $1(14)$ & 0.665 \\
\hline $\begin{array}{l}\text { Omeprazole during intervention } \\
\text { period, } n(\%)\end{array}$ & $43(43)$ & $41(46)$ & $2(29)$ & 0.671 \\
\hline $\begin{array}{l}\text { Duration of omeprazole use during } \\
\text { intervention period, days }\end{array}$ & $4(1,6)$ & $4(2,7)$ & $4.5(3,6)$ & 0.759 \\
\hline $\begin{array}{c}\text { Infants with RBC transfusion during } \\
\text { intervention period, } n(\%)\end{array}$ & $38(38)$ & $32(34)$ & $3(43)$ & 0.821 \\
\hline $\begin{array}{l}\text { Number of RBC transfusions during } \\
\text { intervention period, } n\end{array}$ & $1(1,1)$ & $1(1,1)$ & $1.5(1,2)$ & 0.467 \\
\hline Length of NICU stay, days & $9.5(2,18)$ & $12.0(3,21)$ & $18.0(9,31)$ & 0.166 \\
\hline Length of hospital stay, days & $45(35,55)$ & $46(38,53)$ & $47(26,66)$ * & 0.888 \\
\hline
\end{tabular}

Data are presented as the median (Q25, Q75) unless otherwise stated. All infants were from the control-group; CRIB, clinical risk index for babies with weight at birth $<1500 \mathrm{~g}$; PDA, persistence of ductus arteriosus; $\mathrm{SpO}_{2}$ oxygen saturation measured with a pulse oximeter; RBC, red blood cell; NICU, neonatal intensive care unit. ${ }^{*}$ Not determined in three infants due to death.

Confirmed NEC was lower in infants from the DHA-group compared with the controlgroup (0/100 vs. $7 / 100, p=0.007)$ with a RR of $0.93(95 \%$ CI 0.881 to $0.981, p=0.008)$; there was a risk difference of $-7 \%(95 \% \mathrm{CI}-12.00$ to -1.99$)$, and a number needed to treat of 15 (95\% CI 8.3 to 50). Among the NEC cases, four were female and three were male. The stages of NEC were two cases of IIa, three cases of IIlb, one case of IIIa, and one case of IIIlb. 
The median (minimum, maximum) postnatal age at diagnosis of confirmed NEC was $26(6,29)$ days. The post-enteral feeding time to diagnosis of confirmed NEC was $4(0$, 23) days.

The analysis according to intent-to-treat (ITT) showed a lower level of treatment failure in the DHA-group compared with the control-group (6/105 (6\%) vs. 16/109 (15\%); $p=0.031$ ) with an RR of 0.905 (95\% CI 0.826 to 0.991$)$.

Multivariate analysis identified that being in the control-group was the strongest predictor for developing NEC (adjusted $p=0.002$, Figure 2). Among infants in the controlgroup, the best predictor for developing NEC was the gestational age (adjusted $p=0.043$, Figure 2). The probability of developing NEC was higher in infants older than 29 weeks of gestational age at birth who presented with apnea (adjusted $p=0.014$, Figure 2). The intake of any volume of the own mother's milk was a non-statistically significant, but clinically protective predictor of NEC in the control-group (Figure 3).

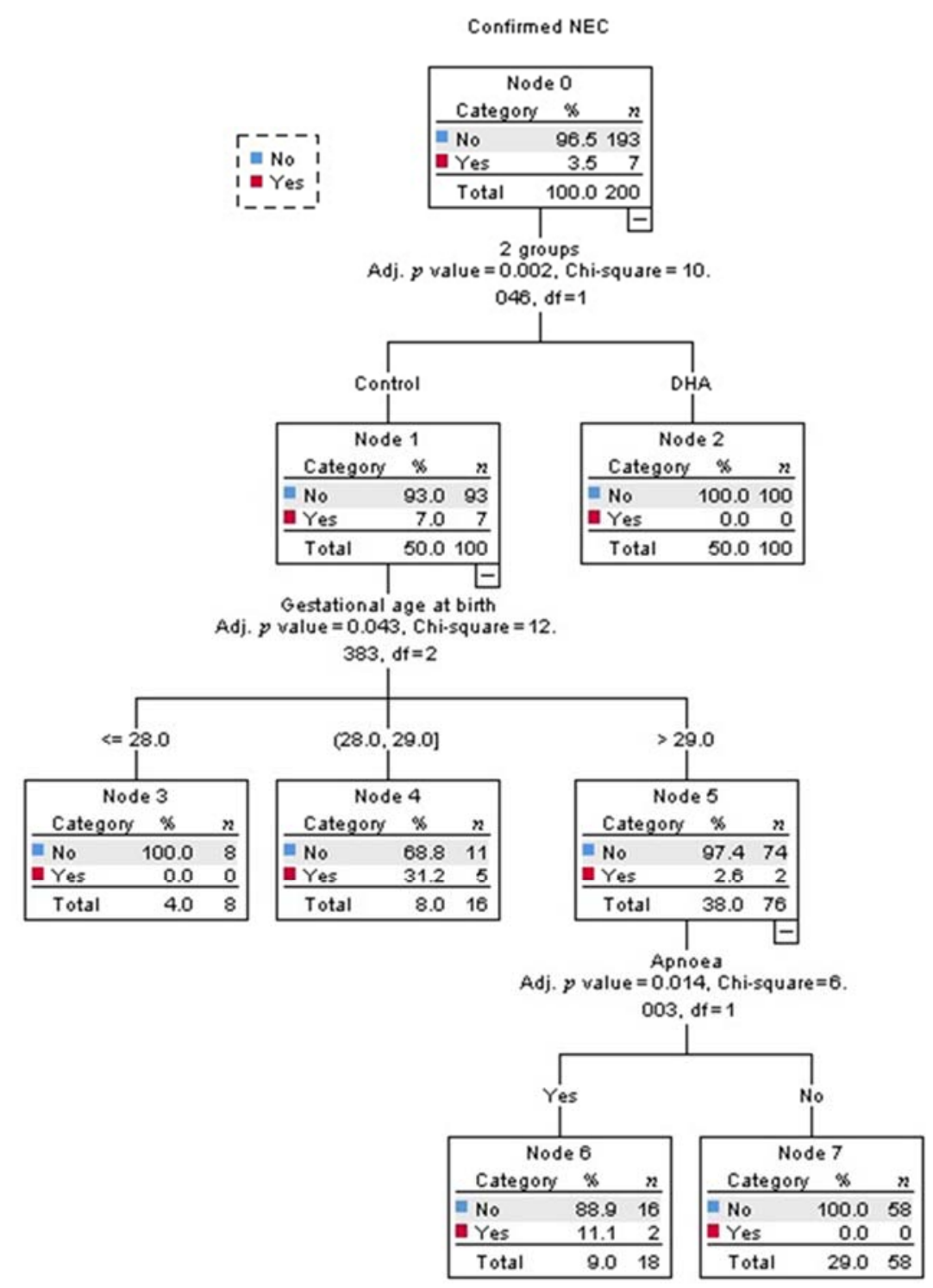

Figure 2. Decision tree obtained from Chi-square automatic interaction detection multiple regression analysis for the prediction of confirmed necrotizing enterocolitis (NEC). The order of the variables, from top to bottom, shows their ranking for the prediction of confirmed NEC; the first was the intervention, the second was gestational age, and the last was presenting apnea. 


\section{Confirmed NEC}
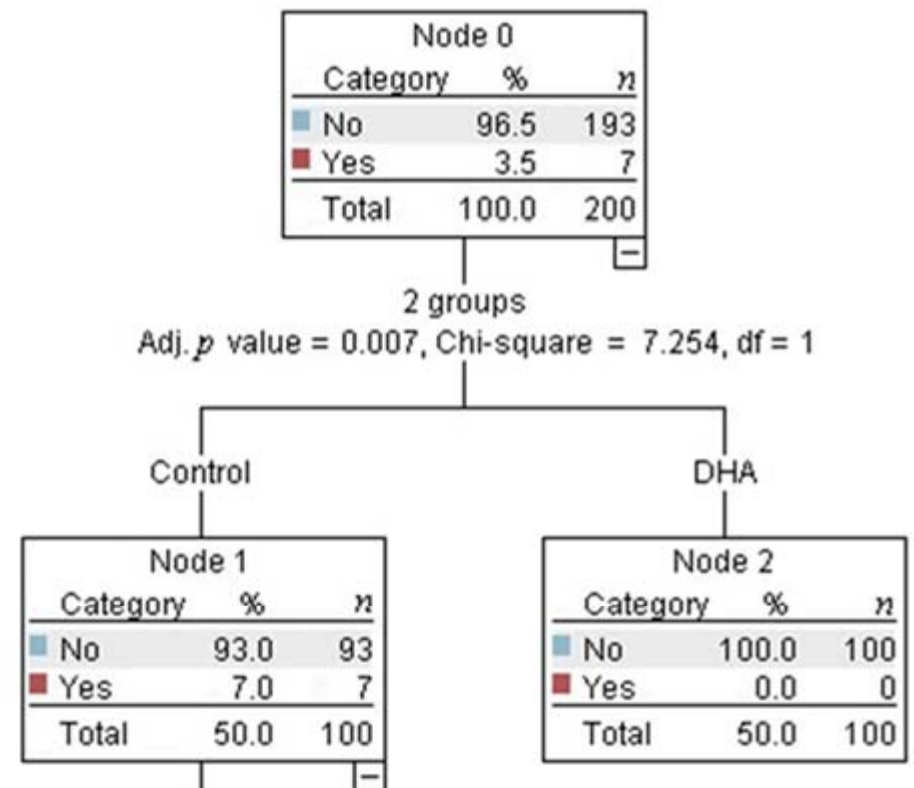

Human milk intake

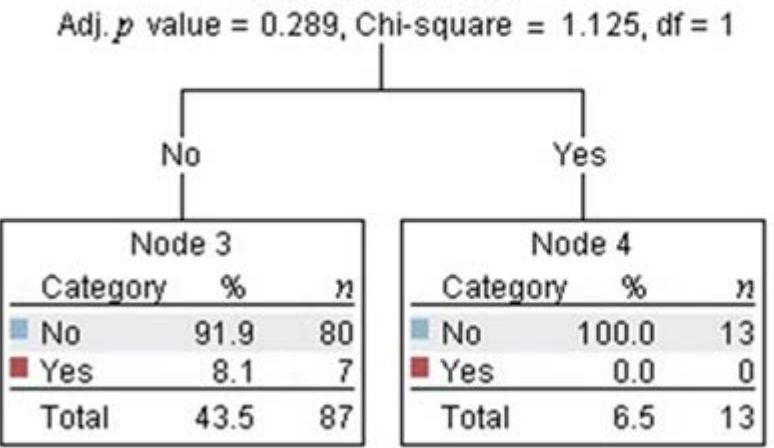

Figure 3. The decision tree obtained from the Chi-square automatic interaction detection multiple regression analysis showed that no infants in the control group who received any volume of human milk developed necrotizing enterocolitis (NEC).

\subsection{Adverse Events}

The median (minimum, maximum) of platelet counts was not different between the DHA and control groups at the baseline and after the intervention $\left(196,000 \mathrm{~mm}^{3}(107,000\right.$, $464,000)$ vs. $182,000(103,000,473,000), p=0.647$ and $345,000 \mathrm{~mm}^{3}(120,000,598,000)$ vs. $347,000(131,000,776,000), p=0.884$, respectively). No infant showed a platelet count $<80,000 \mathrm{~mm}^{3}$.

The per protocol analysis showed no difference in death between the DHA and control groups (1/100 compared to $5 / 100$, one-sided hypothesis $p=0.106)$, with an RR of 0.960 for the DHA-group (95\% CI 0.914 to 1.008). Of the five deaths in the control-group, three were attributable to NEC; the death in the DHA-group was not attributable to NEC. Likewise, in the intent-to-treat analysis, mortality was not different between the DHA-group and control-group ( $3 / 105$ vs. $8 / 109, p=0.119)$ with an $R R=0.954$ for infants in the DHA-group (95\% CI 0.896 to 1.015$)$.

During the total hospital stay, there was no difference between the DHA and control groups in the presence of at least one of the following bleeding entities: periventricular/intraventricular hemorrhage grade $\geq$ II and upper gastrointestinal tract and/or pulmonary bleeding $(68 / 100$ compared with $73 / 100, p=0.438)$. The median of the bleeding events was similar $(1(1,2)$ vs. $1(1,2), p=0.814)$. Periventricular/intraventricular hemor- 
rhage grade $\geq$ II was the most common type of bleeding (57\% in the DHA-group vs. $54 \%$ in the control-group, $p=0.669$ ).

\subsection{Clinical Course and Management}

Covariates from the clinical course and management were similar and there was no collinearity among them. Therefore, data were stratified by the two treatments and the infants with confirmed NEC were employed as an independent group (Table 3).

Regarding nutritional support, total parenteral nutrition did not contain eicosapentaenoic acid, arachidonic acid (AA), or DHA. The volume of fluids, osmolarity ( $239 \mathrm{mOsm} / \mathrm{L})$, and enteral formula were not different among groups. The enteral formula for preterm infants contained $19.4 \mathrm{mg}$ of both DHA and AA per $100 \mathrm{kcal}$; the cumulative intake of DHA and AA from the formula was not different (Table 4). The cumulative intake of DHA and AA estimated from human milk, in those infants receiving human milk during the two weeks of intervention, displayed a median of $0.31(0.12$ to 1.13$) \mathrm{mg} / \mathrm{kg} /$ day and $0.84(0.35$ to 2.52$) \mathrm{mg} / \mathrm{kg} /$ day in the DHA-group, while the control-group received 0.25 (0.12 to 0.38$)$ $\mathrm{mg} / \mathrm{kg} /$ day and 0.35 (0.18 to 0.63$) \mathrm{mg} / \mathrm{kg} /$ day, respectively. Infants in the DHA-group received an additional $75 \mathrm{mg} \mathrm{DHA} / \mathrm{kg}$ body weight/day. The infants who developed NEC showed a non-statistical trend of a higher postnatal age when starting enteral feeding and receiving lower advances in enteral feeding (maximum increases do not exceed $25 \mathrm{~mL} / \mathrm{kg} /$ day), resulting in a statistical trend of lower nutritional support (Table 4). No infant who developed NEC received breastmilk (Table 4), and as consequence, they did not receive fatty acids from human milk (Table 5). Other aspects of nutritional support were not different among groups.

Table 4. Nutritional support of the preterm infants during the hospital stay.

\begin{tabular}{|c|c|c|c|c|}
\hline \multirow[b]{2}{*}{ Nutritional intake variable } & \multicolumn{3}{|c|}{ GROUP } & \multirow[b]{2}{*}{$p$} \\
\hline & $\begin{array}{c}\text { DHA } \\
n=100\end{array}$ & $\begin{array}{c}\text { Control } \\
n=93\end{array}$ & $\begin{array}{l}\text { NEC } \\
n=7\end{array}$ & \\
\hline \multicolumn{5}{|c|}{ Week One of Postnatal Age } \\
\hline Total fluid volume, mL/kg/day & $100(88,108)$ & $97(88,105)$ & $89(75,104)$ & 0.437 \\
\hline Infants receiving TPN before $\mathrm{EF}, n(\%)$ & $50(57)$ & $48(59)$ & $6(86)$ & 0.327 \\
\hline Postnatal age at starting TPN, days & $2.0(1.7,2.4)$ & $2.7(1.0,2.4)$ & $3.0(1.8,4.0)$ & 0.851 \\
\hline Lipid supply by TPN, g/kg/day & $2.0(0.6,3.8)$ & $2.1(0.4,2.9)$ & $2.0(1.4,2.4)$ & 0.877 \\
\hline Postnatal age at starting EF, days & $4.0(2.0,6.5)$ & $4.3(2.5,6.2)$ & $7.0(4.1,9.1)$ & 0.176 \\
\hline Lipid intake-EFF, g/ kg/day & $1.1(0.5,2.3)$ & $1.2(0.6,2.0)$ & $0.5(0.2,1.2)$ & 0.151 \\
\hline \multicolumn{5}{|c|}{ Fatty Acid Intake from EFF, $\mathrm{mg} / \mathrm{kg} /$ day } \\
\hline Linoleic acid & $69(32,231)$ & $100(31,217)$ & $38(11,107)$ & 0.282 \\
\hline Alpha-linolenic acid & $26(10,44)$ & $23(10,39)$ & $9(4,22)$ & 0.154 \\
\hline Arachidonic acid & $5(2,9)$ & $5(2,8)$ & $2(0.8,5)$ & 0.171 \\
\hline Docosahexaenoic acid & $5(2,9)$ & $5(2,8)$ & $2(0.8,5)$ & 0.161 \\
\hline \multicolumn{5}{|c|}{ Week Two of Postnatal Age } \\
\hline Total fluid volume, $\mathrm{mL} / \mathrm{kg} /$ day & $136(125,147)$ & $138(123,147)$ & $127(99,131)$ & 0.081 \\
\hline Lipid supply by TPN, g/kg/day & $1.8(0.8,2.4)$ & $1.8(0.8,2.3)$ & $2.1(1.4,2.5)$ & 0.717 \\
\hline Lipid intake-EFF, $\mathrm{g} / \mathrm{kg} /$ day & $4.5(2.5,5.8)$ & $4.2(2.9,5.7)$ & $1.2(0.4,3.9)$ & 0.059 \\
\hline \multicolumn{5}{|c|}{ Fatty Acid Intake from EFF, mg/kg/day } \\
\hline Linoleic acid & $576(209,880)$ & $506(119,833)$ & $82(21,505)$ & 0.106 \\
\hline Alpha-linolenic acid & $86(48,111)$ & $79(35,108)$ & $23(8,74)$ & 0.064 \\
\hline Arachidonic acid & $17(10,22)$ & $16(7,22)$ & $7(1.4,15)$ & 0.088 \\
\hline Docosahexaenoic acid & $17(10,22)$ & $16(7,22)$ & $7(1.4,15)$ & 0.088 \\
\hline
\end{tabular}


Table 4. Cont.

\begin{tabular}{|c|c|c|c|c|}
\hline \multirow[b]{2}{*}{ Nutritional intake variable } & \multicolumn{3}{|c|}{ GROUP } & \multirow[b]{2}{*}{$p$} \\
\hline & $\begin{array}{c}\text { DHA } \\
n=100\end{array}$ & $\begin{array}{c}\text { Control } \\
n=93\end{array}$ & $\begin{array}{l}\text { NEC } \\
n=7\end{array}$ & \\
\hline \multicolumn{5}{|c|}{ Human Milk Intake } \\
\hline Infants fed any volume of human milk, $n(\%)$ & $18(18)$ & $13(14)$ & 0 & 0.382 \\
\hline Infants fed human milk during first week post-enteral feeding, $n(\%)$ & $11(11)$ & $4(4.2)$ & 0 & 0.157 \\
\hline Intake during first week post-enteral feeding, $\mathrm{mL} / \mathrm{kg} /$ day & $3.9(2.1,10.3)^{\mathrm{a}}$ & $4.9(0.7,9.9)^{b}$ & $0^{\mathrm{c}}$ & 0.003 \\
\hline Infants fed human milk during second week post-enteral feeding, $n(\%)$ & $11(11)$ & $6(6.5)$ & 0 & 0.376 \\
\hline Intake during second week post-enteral feeding, $\mathrm{mL} / \mathrm{kg} /$ day & $8.3(2.4,17.2)^{\mathrm{a}}$ & $5.4(1.8,20.3)^{b}$ & $0^{\mathrm{c}}$ & 0.052 \\
\hline Infants fed human milk during third week post-EF, $n(\%)$ & $9(9)$ & $7(7.5)$ & 0 & 0.679 \\
\hline Intake during third week post-enteral feeding, $\mathrm{mL} / \mathrm{kg} /$ day & $6.7(2.6,23.1)^{\mathrm{a}}$ & $7.9(4.1,13.6)^{\mathrm{a}}$ & $0^{b}$ & 0.029 \\
\hline Infants fed human milk during fourth week post-EF, mL/kg/day, $n(\%)$ & $12(12)$ & $7(7.5)$ & 0 & 0.390 \\
\hline Intake during fourth week post-enteral feeding, $\mathrm{mL} / \mathrm{kg} /$ day & $5.6(2.6,12.7)^{\mathrm{a}}$ & $4.3(1.5,6.2)^{b}$ & $0^{\mathrm{c}}$ & 0.043 \\
\hline Intake during hospital stay, $\mathrm{mL} / \mathrm{kg} /$ day & $14(7,37)$ & $12(3,60)$ & 0 & 0.448 \\
\hline Time required to reach full enteral feeding, days & $15(12,22)$ & $17(12,22)$ & $20(16,46)$ & 0.161 \\
\hline
\end{tabular}

Data are presented as median (Q25, Q75) unless otherwise stated. All infants were from the control group. Different superscripts indicate significant differences among groups ( $p<0.05$, Mann-Whitney-U test). TPN, total parenteral nutrition; EF, enteral feeding; and EEF, enteral feeding from formula. Note: The calculated intake of DHA is from formula in both groups and excludes the additional supplemental intake of $75 \mathrm{mg} / \mathrm{kg} /$ day in the DHA-group.

Table 5. Fatty acid profile of erythrocyte membranes from preterm infants and of human milk (\%weight of total fatty acids).

\begin{tabular}{|c|c|c|c|c|c|c|c|}
\hline Fatty Acid & $\begin{array}{c}\text { DHA } \\
n=100\end{array}$ & $\begin{array}{c}\text { Control } \\
n=93\end{array}$ & $\begin{array}{l}\text { NEC } \\
n=7\end{array}$ & \multirow[t]{2}{*}{$p$} & $\begin{array}{c}\text { DHA } \\
n=100\end{array}$ & $\begin{array}{c}\text { Control } \\
n=93\end{array}$ & $\begin{array}{l}\text { NEC } \\
n=7\end{array}$ \\
\hline \multicolumn{4}{|c|}{ In Baseline Erythrocyte Membranes } & & \multicolumn{3}{|c|}{ In Human Milk during Hospital Stay } \\
\hline Lauric & $\begin{array}{c}0.34 \\
(0.15,0.67)\end{array}$ & $\begin{array}{c}0.38 \\
(0.22,0.79)\end{array}$ & $\begin{array}{c}0.36 \\
(0.15,0.67)\end{array}$ & 0.534 & $\begin{array}{c}7.6 \\
(7.0,9.6)\end{array}$ & $\begin{array}{c}6.6 \\
(6.6,7.2)\end{array}$ & $-*$ \\
\hline Myristic & $\begin{array}{c}0.71 \\
(0.57,1.06)\end{array}$ & $\begin{array}{c}0.80 \\
(0.61,1.24)\end{array}$ & $\begin{array}{c}1.02 \\
(0.71,1.06)\end{array}$ & 0.252 & $\begin{array}{c}9.0 \\
(7.7,9.5)\end{array}$ & $\begin{array}{c}8.8 \\
(8.2,9.4)\end{array}$ & $-*$ \\
\hline Palmitic & $\begin{array}{c}32.5 \\
(29.9,40.7)\end{array}$ & $\begin{array}{c}33.4 \\
(32.2,42.3)\end{array}$ & $\begin{array}{c}31.7 \\
(30.3,48.0)\end{array}$ & 0.463 & $\begin{array}{c}22.0 \\
(20.1,26.9)\end{array}$ & $\begin{array}{c}24.7 \\
(24.2,25.2)\end{array}$ & $-*$ \\
\hline Palmitoleic & $\begin{array}{c}1.12 \\
(0.78,1.42)\end{array}$ & $\begin{array}{c}1.18 \\
(0.80,1.48)\end{array}$ & $\begin{array}{c}1.47 \\
(1.0,2.50)\end{array}$ & 0.055 & $\begin{array}{c}2.3 \\
(2.1,2.6)\end{array}$ & $\begin{array}{c}2.3 \\
(2.2,2.4)\end{array}$ & $-*$ \\
\hline Stearic & $\begin{array}{c}17.4 \\
(15.9,18.9)\end{array}$ & $\begin{array}{c}16.9 \\
(4.3,23.6)\end{array}$ & $\begin{array}{c}17.1 \\
(15.8,19.0)\end{array}$ & 0.485 & $\begin{array}{c}6.6 \\
(6.1,6.7)\end{array}$ & $\begin{array}{c}7.0 \\
(6.6,7.3)\end{array}$ & $-*$ \\
\hline Oleic & $\begin{array}{c}16.7 \\
(15.2,18.8)\end{array}$ & $\begin{array}{c}16.6 \\
(14.6,19.3)\end{array}$ & $\begin{array}{c}16.7 \\
(16.0,18.8)\end{array}$ & 0.894 & $\begin{array}{c}33.7 \\
(31.6,34.9)\end{array}$ & $\begin{array}{c}32.0 \\
(31.9,32.9)\end{array}$ & $-*$ \\
\hline Linoleic & $\begin{array}{c}5.1 \\
(4.0,7.4)\end{array}$ & $\begin{array}{c}5.0 \\
(4.1,7.3)\end{array}$ & $\begin{array}{c}3.6 \\
(2.2,7.3)\end{array}$ & 0.473 & $\begin{array}{c}16.1 \\
(15.9,17.4)\end{array}$ & $\begin{array}{c}15.5 \\
(14.4,17.0)\end{array}$ & $-*$ \\
\hline Alpha-linolenic & $\begin{array}{c}0.12^{\mathrm{a}} \\
(0.09,0.30)\end{array}$ & $\begin{array}{c}0.10^{\mathrm{b}} \\
(0.07,0.17)\end{array}$ & $\begin{array}{c}0.07^{\mathrm{b}} \\
(0.07,0.17)\end{array}$ & 0.042 & $\begin{array}{c}1.2 \\
(1.1,1.5)\end{array}$ & $\begin{array}{c}1.1 \\
(1.0,1.2)\end{array}$ & $-*$ \\
\hline Arachidonic & $\begin{array}{c}14.67 \\
(5.07,20.11)\end{array}$ & $\begin{array}{c}15.50 \\
(5.51,20.2)\end{array}$ & $\begin{array}{c}13.5 \\
(4.3,18.9)\end{array}$ & 0.829 & $\begin{array}{c}0.6 \\
(0.5,0.6)\end{array}$ & $\begin{array}{c}0.5 \\
(0.5,0.6)\end{array}$ & $-*$ \\
\hline Eicosapentaenoic & $\begin{array}{c}0.54 \\
(0.24,0.83)\end{array}$ & $\begin{array}{c}0.53 \\
(0.27,0.70)\end{array}$ & $\begin{array}{c}0.40 \\
(0.31,0.69)\end{array}$ & 0.782 & $\begin{array}{c}0.03^{\mathrm{a}} \\
(0.03,0.06)\end{array}$ & $\begin{array}{c}0.10^{\mathrm{b}} \\
(0.09,0.12)\end{array}$ & $-*$ \\
\hline Nervonic & $\begin{array}{c}2.82 \\
(2.0,3.4)\end{array}$ & $\begin{array}{c}2.62 \\
(2.11,3.4)\end{array}$ & $\begin{array}{c}2.90 \\
(2.0,3.1)\end{array}$ & 0.896 & $\begin{array}{c}0.03 \\
(0.04,0.05)\end{array}$ & $\begin{array}{c}0.03 \\
(0.03,0.04)\end{array}$ & $-*$ \\
\hline Docosahexaenoic & $\begin{array}{c}2.92 \\
(1.2,3.4)\end{array}$ & $\begin{array}{c}2.99 \\
(0.95,3.7)\end{array}$ & $\begin{array}{c}3.0 \\
(2.0,4.0)\end{array}$ & 0.812 & $\begin{array}{c}0.22^{\mathrm{a}} \\
(0.16,0.27)\end{array}$ & $\begin{array}{c}0.35^{\mathrm{b}} \\
(0.33,0.36)\end{array}$ & $-*$ \\
\hline
\end{tabular}

Data are presented as median $(\mathrm{Q} 25, \mathrm{Q} 75) .{ }^{*}$ No infant who developed NEC received human milk. Different superscripts indicate significant differences between groups ( $p<0.05$; Mann-Whitney-U test).

\subsection{Fatty Acid Profile in Erythrocytes and Human Milk}

The fatty acid profile of erythrocytes collected at the baseline was similar between groups, except that alpha-linolenic acid was higher in the DHA-group (Table 5). The human milk received by the infants in the DHA-group contained less eicosapentaenoic acid and 
DHA than the human milk received by the infants in the control-group; the remaining fatty acids were similar for the human milk of both groups, including AA (Table 5).

\section{Discussion}

This trial demonstrates that the enteral administration of $75 \mathrm{mg} / \mathrm{kg} /$ day of DHA starting at the first enteral feed prevents NEC in preterm infants. The efficacy of DHA remained significant in both intent-to-treat and multivariate analysis. To the best of our knowledge, this is the first trial to evaluate the efficacy of isolated enteral DHA administration on confirmed NEC.

Our findings are consistent with those of Lu et al., who found a reduced NEC incidence $(25 \%)$ in neonatal rats that received a formula with DHA ( $0.5 \%$ of fatty acids) compared with the incidence of $35 \%$ in those with AA $(0.7 \%)$ plus DHA $(0.5 \%)$ and $50 \%$ in the control-group [21]. Although that study did not specify whether neonatal rats were preterm, a separate study found similar results in preterm rats: $26 \%$ receiving DHA $(0.5 \%)$ developed NEC, compared with $35 \%$ in a group with AA $(0.7 \%)$ plus DHA $(0.5 \%)$ and $50 \%$ in controls [22]. Those studies suggest a more protective effect of DHA in the absence of AA. Although AA is necessary for growth and cognitive development [11], it is also considered to have some pro-inflammatory properties [12].

Interestingly, an in vitro study using epithelial cells from a resected small intestine from a neonate with NEC demonstrated that treatment with DHA significantly decreased the interleukin (IL)-1beta-induced production of pro-inflammatory cytokines IL-8 and IL-6 compared with controls; AA did not exert an effect on those cells [23].

Our findings are, to some extent, consistent with the results of Carlson et al., who reported a reduced incidence of NEC in infants receiving a formula with AA $(0.41 \%)$ plus DHA $(0.13 \%)$ compared with a control formula, for which the NEC incidence was $2.9 \%$ and $17.6 \%$, respectively [24]. However, that study showed a high incidence of NEC. In another study, Innis et al. found 0, 2, and 1 cases of suspected/confirmed NEC in preterm infants receiving AA $(0.60 \%)$ plus DHA $(0.33 \%)$, DHA $(1 \%)$, or a control formula, respectively [25]. In that study, NEC was sometimes suspected rather than confirmed and the incidence was low.

A meta-analysis [26] and a single study in preterm infants [27] reported no effect of formulas supplemented with AA plus DHA for preventing NEC. The authors of the meta-analysis reported that studies had small sample sizes and a high risk of bias. A large study that administered a dosage of DHA similar to in utero accretion $(60 \mathrm{mg} / \mathrm{kg} /$ day $)$ did not find differences in bronchopulmonary dysplasia (primary outcome) or NEC [28]. It is noteworthy that these studies estimated their power based on primary outcomes other than NEC. Therefore, they may be under-powered for detecting an effect on NEC or they may inaccurately evaluate NEC (some studies do not report how NEC was evaluated). The present study had NEC as its primary outcome, selected a population at risk of NEC, and was powered accordingly. It is possible that the preterm infants from our study may be better responders to DHA compared with infants in other studies. This is speculated because a low maternal intake of DHA results in a poor neonatal status: A study from central Mexico showed a low maternal intake of DHA (median $0.11 \mathrm{mg} /$ day) [29]. In the current study, infant erythrocyte DHA averaged $\sim 3 \%$ of total fatty acids. This is lower than reported in many other studies. For example, in a recent US study, DHA in erythrocytes from 100 one-month-old infants ranged from $3.96 \%$ to $7.75 \%$ [30].

Preterm infants have enterocytes prone to inflammatory responses. This has been explained to be due to exaggerated toll like receptor (TLR) 4 expression and inflammatory signaling and can upregulate platelet-activating factor (PAF) production, which plays an important role in the pathogenesis of NEC. Preterm infants also exhibit under-expression of the inhibitory sub-unit (IKB) of the nuclear transcription factor (NF) $\mathrm{kB}$, which results in the easier synthesis of pro-inflammatory cytokines, chemokines, and other inflammatory mediators [2,31]. Some studies have shown that pro-inflammatory cytokines can weaken intestinal barrier function, escalating inflammation, injury, and gut damage and enabling 
bacteria from the bowel to enter the circulation [32,33]. Moreover, monocytes from preterm infants produce lower levels of IL-10 [34], which is an anti-inflammatory cytokine critical for intestinal homeostasis [5], increasing the risk of exaggerated bowel inflammation.

There is much evidence that DHA reduces inflammation, preventing gut disruption due to several mechanisms, such as decreased NFkB activation; decreased proinflammatory cytokine and PAF synthesis; and the increased production of pro-resolving mediators, such as resolvins, protectins, and maresins, which in turn reduce cytokine production and inflammatory cell recruitment $[12,35]$.

The dose of DHA used in the current study $(75 \mathrm{mg} / \mathrm{kg} /$ day) was used peri-operatively in term neonates who underwent cardiovascular surgery [17]. In that study, circulating monocytes showed an early increase of anti-inflammatory cytokine expression (IL-1 receptor antagonist and IL-10), along with a non-significant increase of pro-inflammatory cytokine expression (IL-1 $\beta$, TNF- $\alpha$, and IL-6) [17]. Therefore, this DHA dosage seems relevant for modifying inflammatory processes and switching to a less inflammatory state. It is biologically plausible that the administration of DHA in anticipation of an inflammatory challenge, as in the current study, represents a narrow window of opportunity for a protective anti-inflammatory strategy. The approach is feasible and inexpensive; the dose of DHA-containing oil can be adjusted and flushed before the milk or enteral formula with a syringe coupled to a feeding tube.

Regarding covariates of the clinical course and medical management, in the current study, the second predictor of NEC (after treatment allocation) in multivariate analysis was gestational age, consistent with the developmental window for the susceptibility of NEC onset $[6,36]$. The third predictor was apnea events, which result in intestinal hypoxia/ischemia. Nonetheless, these were only significant predictors in the controlgroup; there was no predictor of NEC in the DHA-group, since NEC did not occur in that group (Figure 2). All other potential confounders were not significant and therefore, the regression did not select them.

Human milk from mothers with infants in the control-group had higher DHA and eicosapentaenoic acid levels (Table 5), but the estimated cumulative intake of DHA, although negligible, tended to be higher in the DHA-group than in the control-group. This is explained by the fact that the average volume of human milk received in the DHA-group tended to be higher than in the control-group. Additionally, the human milk intake per week did not increase steadily due to critical illness in those infants, but was different among groups (Table 4). Therefore, to evaluate the effect of human milk on confirmed NEC, it was intentionally added along with the treatment allocation in the regression model. Although the effect of human milk on confirmed NEC was not statistically significant, this analysis confirmed a clinically significant effect because it separated those infants from the control-group receiving any volume of human milk and no development of NEC (right square, Figure 3). This analysis was not possible in the DHA group because this group had no NEC events. It is well-known that bioactive factors contained in human milk protect against the onset of NEC [37], giving an absolute risk reduction of $4 \%$ for any stage of NEC for preterm infants [38]. Interestingly, in the present study, the absolute risk reduction with DHA was $7 \%$. Therefore, this intervention should be considered as a strategy for NEC prevention. In this study, preterm birth was often due to maternal critical illness. Therefore, only 31/200 infants received any volume of human milk, 15/200 received it for at least 2 weeks, and no infant was exclusively-fed with human milk.

A previous review identified that antenatal steroids, such as ibuprofen/indomethacin, for the treatment of patent ductus arteriosus were protective factors, while lower oxygen saturations (85-89\%) increased the risk of NEC [39]. In the current study, ibuprofen was also used to treat patent ductus arteriosus in $8 \%$ of the total studied infants, but without differences among groups. Likewise, some causes of ischemic intestinal necrosis, such as a duration of oxygen saturations $<85 \%$, were similar among groups, while major congenital heart disease was an exclusion criterion in the current study [40]. Other known risk factors 
for NEC were also similar among groups [2,6], and no patients had hemoglobin $\leq 8$ $\mathrm{g} / \mathrm{dL}[41]$.

The percentage of alpha-linolenic acid was higher in erythrocytes from the DHAgroup compared with those in the infants from the control-group and NEC-group (Table 5). However, this difference is probably of little relevance because alpha-linolenic acid has low anti-inflammatory potential compared with DHA [42,43].

The current study has several strengths. The trial was blinded, randomized, and placebo controlled. NEC was the primary outcome and was confirmed. The trial was amply powered for this outcome. The DHA and control interventions were delivered by clinical staff and administration was supervised by research staff to ensure compliance. Loss to follow-up was limited. Both intent-to-treat and per protocol analysis were consistent. The DHA dosage was regularly adjusted to maintain similar daily DHA delivery per kg of body weight. The two groups had similar characteristics and covariates, possibly due to the randomization in the blocks of birth weight and recruiting center. Unfortunately, nearly $85 \%$ of mothers were not able to provide their milk for feeding infants, but this allowed us to evaluate the DHA effect without the important protective effect of human milk.

There are also some limitations. We did not assess the fatty acid status at the end of the intervention. Moreover, we did not assess markers of immune function or inflammation or fecal microbiota. Additionally, these results are not generalizable to extremely low birth weight infants because the lower limit of birthweight used for patient recruitment permitted by the Mexican National Committee of Scientific Research was $1 \mathrm{~kg}$. Therefore, whether this intervention is useful to prevent NEC development in preterm infants with a lower weight and gestational age at birth needs to be elucidated.

\section{Conclusions}

A daily enteral dose of DHA for 14 days starting with the first enteral feeding may be a preventive strategy for NEC in preterm infants.

Author Contributions: Conceptualization, M.B.-G. and R.V.-S.; methodology, M.B.-G., P.C.C., R.V.-S., M.R.-C., and L.C.-S.; validation, R.V.-S.; formal analysis, M.B.-G.; investigation, M.B.-G. and A.R.A.-J.; resources, M.B.-G., M.R.-C., L.C.-S., L.C.-R., L.M.-S., G.L.-F., and L.S.-G.; data curation, including randomization and blinding, M.R.-C.; writing_original draft preparation, M.B.-G., R.V.-S., M.R.-C., and P.C.C.; writing-review and editing, P.C.C. and M.R.-C.; supervision, M.B.-G., R.V.-S., and L.S.-G.; project administration, M.B.-G.; funding acquisition, M.B.-G., R.V.-S., M.R.-C., and L.M.-S. All authors have read and agreed to the published version of the manuscript.

Funding: This research was funded by Consejo Nacional de Ciencia y Tecnología (CONACYT), México, grant number Salud-2011-01-161643, in support of the research work (to M.B.-G.).

Institutional Review Board Statement: The study was conducted according to the guidelines of the Declaration of Helsinki and was approved by the Institutional Ethics Committee (National Committee of Scientific Research) of the Instituto Mexicano del Seguro Social (protocol code CNIC-2012-785-007, date of approval 28 February 2012).

Informed Consent Statement: Informed consent was obtained from parents or tutors of all subjects involved in the study.

Clinical Trial registration ID: NCT01745510. https://clinicaltrials.gov/ct2/show /NCT01745510.

Data Availability Statement: Data can be made available by contacting the corresponding author.

Acknowledgments: We thank the parents who agreed to participate on behalf of their infants. We also thank Mardia Lopez-Alarcón, José Magdaleno-Lara, José Ramón Jimenez, Marisol Millán, José M. González, Jorge I. Gutiérrez, Xóchitl Rodríguez, Elvira Palacios, neonatologists, and nursery staff for their contribution and support. Moreover, we thank Julio Cesar Flores Castro from Experiencia Analítica, México City, México, for statistical advice and support.

Conflicts of Interest: P.C.C. acts as a consultant to BASF AS, Smartfish, DSM, Cargill, Danone/Nutricia, and Fresenius-Kabi. All other authors declare no conflicts of interest. The funders had no role in 
the design of the study; in the collection, analyses, or interpretation of data; in the writing of the manuscript; or in the decision to publish the results.

\section{References}

1. Gupta, A.; Paria, A. Etiology and medical management of NEC. Early Hum. Dev. 2016, 97, 17-23. [CrossRef]

2. Neu, J.; Walker, W.A. Necrotizing enterocolitis. N. Engl. J. Med. 2011, 364, 255-264. [CrossRef]

3. Jones, I.H.; Hall, N.J. Contemporary outcomes for infants with necrotizing enterocolitis-a systematic review. J. Pediatr. 2020, 220, 86-92.e83. [CrossRef]

4. Bazacliu, C.; Neu, J. Necrotizing enterocolitis: Long term complications. Curr. Pediatr. Rev. 2019, 15, 115-124. [CrossRef] [PubMed]

5. Denning, T.L.; Bhatia, A.M.; Kane, A.F.; Patel, R.M.; Denning, P.W. Pathogenesis of NEC: Role of the innate and adaptive immune response. Semin. Perinatol. 2017, 41, 15-28. [CrossRef]

6. Neu, J.; Pammi, M. Pathogenesis of NEC: Impact of an altered intestinal microbiome. Semin. Perinatol. 2017, 41, 29-35. [CrossRef] [PubMed]

7. Smith, S.L.; Rouse, C.A. Docosahexaenoic acid and the preterm infant. Matern. Health Neonatol. Perinatol. 2017, 3, 22. [CrossRef] [PubMed]

8. Martin, C.R.; Dasilva, D.A.; Cluette-Brown, J.E.; Dimonda, C.; Hamill, A.; Bhutta, A.Q.; Coronel, E.; Wilschanski, M.; Stephens, A.J.; Driscoll, D.F.; et al. Decreased postnatal docosahexaenoic and arachidonic acid blood levels in premature infants are associated with neonatal morbidities. J. Pediatr. 2011, 159, 743-749.e1-2. [CrossRef]

9. Brenna, J.T.; Varamini, B.; Jensen, R.G.; Diersen-Schade, D.A.; Boettcher, J.A.; Arterburn, L.M. Docosahexaenoic and arachidonic acid concentrations in human breast milk worldwide. Am. J. Clin. Nutr. 2007, 85, 1457-1464. [CrossRef]

10. Moltó-Puigmartí, C.; Castellote, A.I.; Carbonell-Estrany, X.; López-Sabater, M.C. Differences in fat content and fatty acid proportions among colostrum, transitional, and mature milk from women delivering very preterm, preterm, and term infants. Clin. Nutr. 2011, 30, 116-123. [CrossRef] [PubMed]

11. Koletzko, B.; Bergmann, K.; Brenna, J.T.; Calder, P.C.; Campoy, C.; Clandinin, M.T.; Colombo, J.; Daly, M.; Decsi, T.; Demmelmair, H.; et al. Should formula for infants provide arachidonic acid along with DHA? A position paper of the European Academy of Paediatrics and the Child Health Foundation. Am. J. Clin. Nutr. 2020, 111, 10-16. [CrossRef]

12. Frost, B.L.; Caplan, M.S. Can fish oil reduce the incidence of necrotizing enterocolitis by altering the inflammatory response? Clin. Perinatol. 2019, 46, 65-75. [CrossRef]

13. World Medical Association. World Medical Association Declaration of Helsinki: Ethical principles for medical research involving human subjects. JAMA 2013, 310, 2191-2194. [CrossRef] [PubMed]

14. Regulation of the General Law of Health in maters of Research for Health [REGLAMENTO de la Ley General de Salud en Materia de Investigación para la Salud. Diario Oficial de la Federación]. Published 7 February 1984. Available online: http://www.salud.gob.mx/unidades/cdi/nom/compi/rlgsmis.html (accessed on 13 January 2021).

15. Saghaei, M. Random allocation software for parallel group randomized trials. BMC Med. Res. Methodol. 2004, 4, 26. [CrossRef]

16. Bernabe-Garcia, M.; Villegas-Silva, R.; Villavicencio-Torres, A.; Calder, P.C.; Rodriguez-Cruz, M.; Maldonado-Hernandez, J.; Macias-Loaiza, D.; Lopez-Alarcon, M.; Inda-Icaza, P.; Cruz-Reynoso, L. Enteral docosahexaenoic acid and retinopathy of prematurity: A randomized clinical trial. J. Parent. Enter. Nutr. 2019, 43, 874-882. [CrossRef]

17. Bernabe-Garcia, M.; Lopez-Alarcon, M.; Villegas-Silva, R.; Mancilla-Ramirez, J.; Rodriguez-Cruz, M.; Maldonado-Hernandez, J.; Chavez-Rueda, K.A.; Blanco-Favela, F.; Espinoza-Garcia, L.; Lagunes-Salazar, S. Beneficial effects of enteral docosahexaenoic acid on the markers of inflammation and clinical outcomes of neonates undergoing cardiovascular surgery: An intervention study. Ann. Nutr. Metab. 2016, 69, 15-23. [CrossRef] [PubMed]

18. Walsh, M.C.; Kliegman, R.M. Necrotizing enterocolitis: Treatment based on staging criteria. Pediatr. Clin. N. Am. 1986, 33, 179-201. [CrossRef]

19. The International Neonatal Network. The CRIB (clinical risk index for babies) score: A tool for assessing initial neonatal risk and comparing performance of neonatal intensive care units. The International Neonatal Network. Lancet 1993, 342, 193-198. [CrossRef]

20. Evershed, R. Gas chromatography of lipids. In Lipid Analysis. A Practical Approach; Hamilton, S., Hamilton, R.J., Eds.; Oxford University Press: Oxford, UK, 1992; pp. 113-151.

21. Lu, J.; Jilling, T.; Li, D.; Caplan, M.S. Polyunsaturated fatty acid supplementation alters proinflammatory gene expression and reduces the incidence of necrotizing enterocolitis in a neonatal rat model. Pediatr. Res. 2007, 61, 427-432. [CrossRef]

22. Ohtsuka, Y.; Okada, K.; Yamakawa, Y.; Ikuse, T.; Baba, Y.; Inage, E.; Fujii, T.; Izumi, H.; Oshida, K.; Nagata, S.; et al. Omega-3 fatty acids attenuate mucosal inflammation in premature rat pups. J. Pediatr. Surg. 2011, 46, 489-495. [CrossRef] [PubMed]

23. Wijendran, V.; Brenna, J.T.; Wang, D.H.; Zhu, W.; Meng, D.; Ganguli, K.; Kothapalli, K.S.; Requena, P.; Innis, S.; Walker, W.A. Long-chain polyunsaturated fatty acids attenuate the IL-1beta-induced proinflammatory response in human fetal intestinal epithelial cells. Pediatr. Res. 2015, 78, 626-633. [CrossRef] [PubMed]

24. Carlson, S.E.; Montalto, M.B.; Ponder, D.L.; Werkman, S.H.; Korones, S.B. Lower incidence of necrotizing enterocolitis in infants fed a preterm formula with egg phospholipids. Pediatr. Res. 1998, 44, 491-498. [CrossRef] [PubMed] 
25. Innis, S.M.; Adamkin, D.H.; Hall, R.T.; Kalhan, S.C.; Lair, C.; Lim, M.; Stevens, D.C.; Twist, P.F.; Diersen-Schade, D.A.; Harris, C.L.; et al. Docosahexaenoic acid and arachidonic acid enhance growth with no adverse effects in preterm infants fed formula. $J$. Pediatr. 2002, 140, 547-554. [CrossRef]

26. Smithers, L.G.; Gibson, R.A.; McPhee, A.; Makrides, M. Effect of long-chain polyunsaturated fatty acid supplementation of preterm infants on disease risk and neurodevelopment: A systematic review of randomized controlled trials. Am. J. Clin. Nutr. 2008, 87, 912-920. [CrossRef] [PubMed]

27. Henriksen, C.; Haugholt, K.; Lindgren, M.; Aurvag, A.K.; Ronnestad, A.; Gronn, M.; Solberg, R.; Moen, A.; Nakstad, B.; Berge, R.K.; et al. Improved cognitive development among preterm infants attributable to early supplementation of human milk with docosahexaenoic acid and arachidonic acid. Pediatrics 2008, 121, 1137-1145. [CrossRef] [PubMed]

28. Collins, C.T.; Makrides, M.; McPhee, A.J.; Sullivan, T.R.; Davis, P.G.; Thio, M.; Simmer, K.; Rajadurai, V.S.; Travadi, J.; Berry, M.J.; et al. Docosahexaenoic acid and bronchopulmonary dysplasia in preterm infants. N. Engl. J. Med. 2017, 376, 1245-1255. [CrossRef]

29. Parra-Cabrera, S.; Moreno-Macias, H.; Mendez-Ramirez, I.; Schnaas, L.; Romieu, I. Maternal dietary omega fatty acid intake and auditory brainstem-evoked potentials in Mexican infants born at term: Cluster analysis. Early Hum. Dev. 2008, 84, 51-57. [CrossRef] [PubMed]

30. Farahnak, Z.; Yuan, Y.; Vanstone, C.A.; Weiler, H.A. Maternal and neonatal red blood cell n-3 polyunsaturated fatty acids inversely associate with infant whole-body fat mass assessed by dual-energy X-ray absorptiometry. Appl. Physiol. Nutr. Metab. 2020, 45, 318-326. [CrossRef]

31. Hackam, D.J.; Afrazi, A.; Good, M.; Sodhi, C.P. Innate immune signaling in the pathogenesis of necrotizing enterocolitis. Clin. Dev. Immunol. 2013, 2013, 475415. [CrossRef]

32. Bruewer, M.; Luegering, A.; Kucharzik, T.; Parkos, C.A.; Madara, J.L.; Hopkins, A.M.; Nusrat, A. Proinflammatory cytokines disrupt epithelial barrier function by apoptosis-independent mechanisms. J. Immunol. 2003, 171, 6164-6172. [CrossRef]

33. Halpern, M.D.; Clark, J.A.; Saunders, T.A.; Doelle, S.M.; Hosseini, D.M.; Stagner, A.M.; Dvorak, B. Reduction of experimental necrotizing enterocolitis with anti-TNF-alpha. Am. J. Physiol. Gastrointest. Liver Physiol. 2006, 290, G757-G764. [CrossRef]

34. Chheda, S.; Palkowetz, K.H.; Garofalo, R.; Rassin, D.K.; Goldman, A.S. Decreased interleukin-10 production by neonatal monocytes and T cells: Relationship to decreased production and expression of tumor necrosis factor-alpha and its receptors. Pediatr. Res. 1996, 40, 475-483. [CrossRef]

35. Calder, P.C. n-3 PUFA and inflammation: From membrane to nucleus and from bench to bedside. Proc. Nutr. Soc. 2020, 79, 404-416. [CrossRef]

36. Llanos, A.R.; Moss, M.E.; Pinzon, M.C.; Dye, T.; Sinkin, R.A.; Kendig, J.W. Epidemiology of neonatal necrotising enterocolitis: A population-based study. Paediatr. Perinat. Epidemiol. 2002, 16, 342-349. [CrossRef] [PubMed]

37. Patel, A.L.; Kim, J.H. Human milk and necrotizing enterocolitis. Semin. Pediatr. Surg. 2018, 27, 34-38. [CrossRef]

38. Miller, J.; Tonkin, E.; Damarell, R.A.; McPhee, A.J.; Suganuma, M.; Suganuma, H.; Middleton, P.F.; Makrides, M.; Collins, C.T. A systematic review and meta-analysis of human milk feeding and morbidity in very low birth weight infants. Nutrients 2018, 10, 707. [CrossRef]

39. Xiong, T.; Maheshwari, A.; Neu, J.; Ei-Saie, A.; Pammi, M. An Overview of systematic reviews of randomized-controlled trials for preventing necrotizing enterocolitis in preterm infants. Neonatology 2020, 117, 46-56. [CrossRef] [PubMed]

40. Spinner, J.A.; Morris, S.A.; Nandi, D.; Costarino, A.T.; Marino, B.S.; Rossano, J.W.; Shamszad, P. Necrotizing enterocolitis and associated mortality in neonates with congenital heart disease: A multi-institutional study. Pediatr. Crit. Care Med. 2020, 21, 228-234. [CrossRef]

41. Patel, R.M.; Knezevic, A.; Shenvi, N.; Hinkes, M.; Keene, S.; Roback, J.D.; Easley, K.A.; Josephson, C.D. Association of red blood cell transfusion, anemia, and necrotizing enterocolitis in very low-birth-weight infants. JAMA 2016, 315, 889-897. [CrossRef] [PubMed]

42. Marion-Letellier, R.; Butler, M.; Dechelotte, P.; Playford, R.J.; Ghosh, S. Comparison of cytokine modulation by natural peroxisome proliferator-activated receptor gamma ligands with synthetic ligands in intestinal-like Caco-2 cells and human dendritic cellspotential for dietary modulation of peroxisome proliferator-activated receptor gamma in intestinal inflammation. Am. J. Clin. Nutr. 2008, 87, 939-948. [CrossRef] [PubMed]

43. Baker, E.J.; Valenzuela, C.A.; De Souza, C.O.; Yaqoob, P.; Miles, E.A.; Calder, P.C. Comparative anti-inflammatory effects of plantand marine-derived omega-3 fatty acids explored in an endothelial cell line. Biochim. Biophys. Acta Mol. Cell Biol. Lipids 2020 1865, 158662. [CrossRef] [PubMed] 